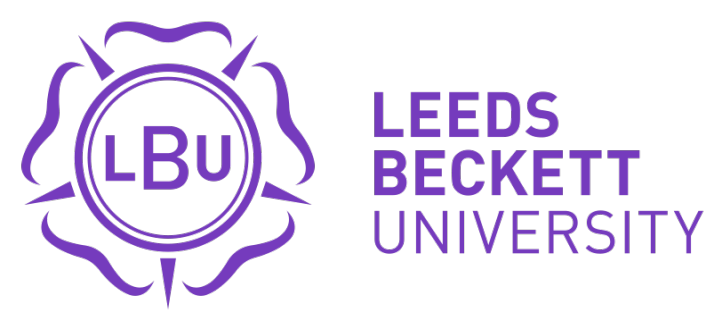

Citation:

Moon, C and SánchezRodríguez, Á (2020) Cultural influences on normative reactions to incivility: comparing individuals from South Korea and Spain. International Journal of Conflict Management. ISSN 1044-4068 DOI: https://doi.org/10.1108/IJCMA-05-2020-0096

Link to Leeds Beckett Repository record:

https://eprints.leedsbeckett.ac.uk/id/eprint/7062/

Document Version:

Article (Accepted Version)

Creative Commons: Attribution-Noncommercial 4.0

The aim of the Leeds Beckett Repository is to provide open access to our research, as required by funder policies and permitted by publishers and copyright law.

The Leeds Beckett repository holds a wide range of publications, each of which has been checked for copyright and the relevant embargo period has been applied by the Research Services team.

We operate on a standard take-down policy. If you are the author or publisher of an output and you would like it removed from the repository, please contact us and we will investigate on a case-by-case basis.

Each thesis in the repository has been cleared where necessary by the author for third party copyright. If you would like a thesis to be removed from the repository or believe there is an issue with copyright, please contact us on openaccess@leedsbeckett.ac.uk and we will investigate on a case-by-case basis. 
[*This article was accepted on $15^{\text {th }}$ August 2020]

This accepted version was deposited under the Creative Commons Attribution Non-commercial International Licence 4.0 (CC BY-NC 4.0)

\title{
Cultural Influences on Normative Reactions to Incivility: Comparing Individuals from South Korea and Spain
}

\author{
Chanki Moon ${ }^{1,2}$ and Ángel Sánchez-Rodríguez ${ }^{3,4}$
}

\author{
${ }^{1}$ School of Social Science, Leeds Beckett University, UK \\ ${ }^{2}$ School of Psychology, University of Kent, UK \\ ${ }^{3}$ Centro de Investigación Mente Cerebro y Comportamiento (CIMCYC), University of Granada, \\ Granada, Spain \\ ${ }^{4}$ University of Salamanca, Salamanca, Spain,
}

WORD COUNT: 11,992 (incl. abstract, references, tables, figures and appendices)

Cite as: Moon, C. and Sánchez-Rodríguez, Á. (2020), "Cultural influences on normative reactions to incivility: comparing individuals from South Korea and Spain", International Journal of Conflict Management, Vol. ahead-of-print No. ahead-of-print. https://doi.org/10.1108/IJCMA-05-2020-0096

Author Note

Correspondence concerning this article should be addressed to Chanki Moon, School of Social Science, Leeds Beckett University, Portland Way, Leeds, UK, LS1 3HE. Email:

c.moon@leedsbeckett.ac.uk or Ángel Sánchez-Rodríguez, University of Salamanca, Patio de Escuelas, 1, 37008Salamanca, Spain Email: angelsr@usal.es

\section{Ethics Statement:}

This study was approved by the institutional review board (IRB), Chonnam National University, South Korea. IRB No. (1040198-180418-HR-025-02)

\section{Funding:}

The authors received no specific funding for this work.

\section{Conflict of Interest Statement:}

The authors declare that the research was conducted in the absence of any commercial or financial relationships that could be construed as a potential conflict of interest. 


\begin{abstract}
Purpose: Antecedents and influences of workplace incivility have recently been studied in many areas of research but there is still lack of consideration for the impact of culture. Theoretical considerations for the present research are based on the cultural dimensions of power distance and tightness/looseness because the collective levels of power distance are similar between Korea and Spain, but the collective levels of tightness/looseness are different between the two countries. The present research examined whether individuals' occupational position affects their normative reactions to incivility differently.
\end{abstract}

Design/methodology/approach: Participant (victim)'s (those who react to uncivil behaviors) social power (low vs. high) and perpetrator's (those who exhibit uncivil behaviors) social power (low vs. high) were experimentally manipulated; all participants were randomly assigned to one of four perpetrator $\mathrm{x}$ victim conditions in relation to hierarchical positions $\left(N_{\mathrm{tot}}=467\right)$.

Findings: The results suggest that the level of social and personal acceptability was greater either among Koreans than Spanish at a collective level or among people who endorsed higher power distance and tightness values. All in all, the findings highlight cultural influences on the importance of social hierarchy as a factor that can impact the people's normative reactions to incivility.

Originality/value: The findings broaden our understanding of psychology of employees in relation to incivility, by simultaneously considering the influences of culture (power distance and tightness/looseness) and social power.

Keywords: Cultural differences, occupational position, incivility, high power distance, tightness/looseness

Paper type: Research paper. 
Imagine that you work in a company and one of your colleagues behave in an uncivil manner to you. How would you feel? You may feel uncomfortable and angry. Indeed, interpersonal mistreatments (i.e., incivility, bullying, harassment, abusive supervision) are associated with many unpleasant affective reactions including depression, frustration, a lowered self-esteem, anxiety, and burnout, which can lead negative organizational consequences such as lowered job satisfaction and increased turnover intention (e.g., Bowling and Beehr, 2006). However, your reactions might be quite different depending on your cultural background. Cross-cultural reviews suggest that cultural values have an impact on how employees react to various aspects of their work environment (Gelfand et al., 2007; Tsui et al., 2007) as well as how employees react to the relationship between subordinates and supervisors (Günsoy, 2019; Lawler et al., 2008).

Previous research found that that individuals from high power distance culture-i.e., South Korea (vs. low power distance cultures: United Kingdom) are likely to accept the uncivil behaviors when these are displayed by those who hold a position of power (Moon $e t$ $a l ., 2018 \mathrm{c})$. Although power distance itself has an impact on individual's normative reaction to incivility in hierarchical relationships, it is important to understand also the role of cultural differences in social norms' strength considering the incivility is seen as a violation of the social norm (i.e., tight/loose cultures, Gelfand et al., 2006; Gelfand et al., 2011). Therefore, in the current research, we aim to compare the reactions to incivility by individuals from South Korea and Spain because both South Korea and Spain are cultures with high power distance but how strictly or loosely social norms operate in the society are different between the two countries (South Korea: a tight culture, Spain: a loose culture) (Hofstede et al., 2010; Gelfand et al., 2006; 2011).

\section{Incivility Reactions}

Incivility is defined as a low-intensity interpersonal mistreatment (e.g., 
discourteousness and condescension) that violates norms for mutual respect and exhibit disregard for others (Andersson and Pearson, 1999). Most workers experience incivility in general (Cortina, 2008; Porath and Pearson, 2013) and it is on the rise in organizations (Porath and Pearson, 2013; Schilpzand et al., 2016). Workplace incivility has been found to influence on work (e.g., performance, job satisfaction, disengagement) and nonwork outcomes (e.g., stress, emotional exhaustion, work-life imbalance) (see Irum et al., 2020 for a review). For example, studies have shown that experiencing of interpersonal mistreatment (incivility) in the workplace can induce negative emotions in individuals (Porath and Pearson, 2012). Moreover, incivility has an impact on productivity and the cost of lost productivity (Hutton and Gates, 2008; Lewis and Malecha, 2011; Porath and Pearson, 2010).

Incivility reactions can be influenced by dispositional (e.g., narcissism), situational (e.g., power and status), organizational (e.g., norm and climate) and cultural factors. For example, narcissistic individuals are more likely to be angry rather than guilty when experienced workplace incivility (Liu et al., 2020). Organizational norm can also affect employee's perceptions of and reactions toward incivility (Moon et al. 2018c; Schilpzand et al., 2016; Tepper et al., 2017). Although dispositional and organizational factors can affect people's responses to incivility, the present research focuses on the situational and cultural factors to understand people's normative reactions to incivility.

Regarding situational factor, incivility reactions are highly conditioned by the perpetrator hierarchy position as well as the target. For example, the positive association between daily experience of incivility and its emotional effect with embarrassment is strong when the perpetrator is powerful (Hershcovis et al., 2017). Incivility is more frequently observed as a downward phenomenon (e.g., Cortina et al., 2001), and this can be found across Western and East Asian cultures (Lim and Lee, 2011; Moon et al., 2018c; Pearson et al., 2000; Torelli and Shavitt, 2010). Undesirable behavior such as incivility may be 
promoted by power because powerful individuals are less likely to be restrained by rules and obligations (Bowles and Gelfand, 2010; Galinsky et al., 2008). However, powerless individuals have less legitimate power (Johnson and Indvik, 2001; Pearson and Porath, 2005). Therefore, power and job position can be antecedent to interpersonal mistreatment. In organizational contexts, individuals in lower positions are less likely to take revenge or to express aggression toward those in higher positions due to the imbalance of power and control between them (Aquino et al., 1999; Aquino et al., 2001). Alternatively, people in lower position tend to express their anger indirectly throughout social sharing (Petkanopoulou et al., 2019). By contrast, people in higher positions can express their emotions more freely than those in lower positions (Conway et al., 1999; Lively, 2000). Although individuals' reactions to incivility can be dependent upon situational factors such as power and occupational status, this can be also dependent upon the culture in which people grew up.

\section{Cultural Differences}

In the face of globalization, there has been constant debate about whether cultures converge or diverge (see Gelfand et al. 2017). Some scholars argued that the world is getting flat due to the influence of globalization (Friedman, 2005) but the other argued against that globalization producing homogeneity (Klein, 2002). Although there are cultural changes that lead cultures to converge (e.g., increasing individualistic values and practices around the world, Santos et al., 2017), cultural differences continue to exist between and within countries (House et al., 2004).

In the present research, we focus on the cultural dimensions of power distance and tight/loose social norms to understand how culture affects people's normative reactions to incivility displayed by those in higher (vs. lower) position in the workplace settings. Power distance describes the extent to which individuals accept the existence of hierarchical 
differences and legitimize unequally distributed power in a society (Hofstede et al., 2010; House et al., 2004). Higher power distance societies tend to be hierarchically structured and characterized by subordinates' dependence on authority figures and values of respect and obedience. In contrast, lower power distance societies tend to be more egalitarian and characterized by interdependence between subordinates and authorities (e.g., Hofstede et al., 2010; Johnson et al., 2005; Tyler et al., 2000). Studies have demonstrated that in the high power distance context (e.g., China), the negative influence of downward mistreatment can be moderated by individuals' high power distance orientation, which suggests that individuals' psychological reactions to interpersonal mistreatment as victims are affected by cultural norms (Lian et al., 2012; Lin et al., 2013; Liu et al., 2013; Wang et al., 2012). This finding has been extended with cross-cultural comparisons between high versus low power distance contexts. For example, power distance explained that subordinates respond less negatively to abusive supervisors in East Asian countries than in Anglo countries (Vogel et al., 2015; cf. Kernan et al., 2011). More recently, Moon et al. (2018c) showed that individuals from high (vs. low) power distance culture are likely to accept the uncivil behaviors when these are displayed by those who hold a position of power, but across cultures, people perceive incivility by a powerful individual was more common than incivility by a powerless individual. Thus, given the imbalance of position of power between subordinates and senior colleagues, it would be more common and more normative for power holders to show uncivil behaviors in high power distance countries (Tepper, 2007).

Furthermore, cultural influences have been observed in the context of conflict management and negotiation (e.g., e.g., Caputo, 2013; Caputo et al., 2019; Caputo et al., 2018; Gunkel et al., 2016). For example, power distance has positive associations with avoiding and forcing style as conflict management (Caputo et al., 2018), as well as a positive relationship with competitive style of negotiation (Caputo et al., 2019). 
Cultures also differ in their social norm's strength and tolerance to their deviation (Gelfand et al., 2011). Social norm is defined as "behaviors of group members that act as implicit rules, considered to be both descriptive of what group members are and prescriptive (injunctive) of how they should be" (Fiske, 2004, p. 484). Moreover, norms exist as selfexpectation or personal norms; individuals comply with social norms due to the enforcement but adhere to personal norms due to the expression of their values (Schwartz, 1977; see also Morris et al., 2015). In some cultures, social norms are clear and strong (i.e., tight culture), but in others social norms are weak and accompanied by lower intolerance for any deviation from the expected normative behaviors (i.e., loose cultures, Gelfand et al., 2006; Gelfand et $a l .$, 2011). For example, a cross-cultural research demonstrated that whilst European countries such as Spain and the Netherlands with scores of 5.4 and 3.3, respectively, are relatively loose compared with the reference point for the tightness score (6.5), East Asian countries such as Korea, China, and Japan with scores of 10.0, 7.9 and 8.6, respectively, are relatively tight compared with the reference point (Gelfand et al., 2011). Differences in tight and loose cultures have important implications. For instance, recently Gelfand et al. (2020) found that tight cultures have addressed more efficiently COVID-19 pandemic.

\section{Overviews of the Present Research}

In the present research, for the first time, we sought to establish the individuals' reactions to incivility by comparing individuals from South Korea and Spain. According to the power distance index (Hofstede et al., 2010), both Korea and Spain can be clustered as a hierarchical society (i.e., high power distance culture), but the score of Korea (60) is somewhat higher than the one of Spain (57), suggesting that Korean society may be relatively more hierarchical. However, Korea with the score of 10.0 is relatively tight compared to Spain with the score of 5.4 which might be considered a loose culture (Gelfand et al., 2011). Comparing South Korea with Spain allow us to explore the interaction between these 
two cultural dimensions. Therefore, we aim to test whether participants reactions to a violation of social norm in a hierarchical context are different in both countries South Korea and Spain. To do so, we tested whether there are differences between Korea and Spain on people's reactions to uncivil behaviors depending on social power. Specifically, we conducted an experiment manipulating participant's (those who react to uncivil behavior) social power (high vs. low) and target's (those who exhibit uncivil behaviors) social power (high vs. low) in the Korean and Spanish samples.

Hierarchy as social norm might play important role in social interactions across cultural groups, but the hierarchical norms might be much strongly embedded in Korean society than in Spanish society. Based on this, we predicted that compared to Spanish, Korean individuals will pay more attention to the hierarchical position occupied by perpetrators in organizations and regulate their emotional responses in line with the cultural necessities of fitting into one's role and social context.

Given the contrast between South Korean and Spain in the strength on social norms, we aim to deep in the role of social norms to explain the differences between these countries. Based on the role of subjective representations of norms to understand cultural dynamics (Moon et al., 2018c; Morris et al., 2015), we focused on perceived descriptive norm, perceived injunctive norm, and personal norm.

\section{Method}

\section{Preregistered design and hypotheses}

We conducted a 2 (Participant's Social Power: high vs. low) x 2 (Target's Social Power: high vs. low) between subjects' experiment in South Korea and Spain. Our hypotheses were that Participant's Social Power (high vs. low) and Target's Social Power (high vs. low) would have different effects on perceived discomfort with uncivil behavior in 
Korea and Spain (see preregistration https://osf.io/g9qc7/?view_only=c692eb28dbee440d8131d839f3f99316). Particularly:

(1) In Korea, high target's social power would cause less perceived discomfort than Low target's Social Power. Furthermore, we expect that discomfort level would be higher when the target's social power is relatively higher than the participant's one as compared to the target's social power is the same as the participant's one, which is interaction effect. But the main effect of participant's social power is not expected.

(2) In Spain, an interactive effect between target's social power and participant's social power is expected. Perceived discomfort would be higher when participant and target are in different power position (i.e. low target's social power and high participant's social power or high target's social power and low participant's social power) than when participant and target are in the same power position (i.e. low target and participant's social power or high target and participant's social power).

\section{Sample size calculation and participants}

We conducted a priori sample size analysis using $\mathrm{G}^{*}$ Power (Faul et al., 2009) to test an ANOVA: Fixed effects, special, main effects and interactions with eight groups. According to our Power analysis to estimate a medium effect size ( $f=0.23)$ with a $p$-values of $<.05$, we need 420 participants to have a Power of $95 \%$ ( 279 to get $80 \%$ of power). Given that we anticipated that some participants would be foreign, and they would not have good skills with the Korean and Spanish language respectively, we included as exclusion criterion that those who are not native Korean speakers in Korea and Spanish speakers in Spain will be excluded.

\section{Participants and Design}

Participants were recruited from a university in South Korea $(N=347)$ and in Spain $(N=224)$ but we excluded 17 participants who were not identified as Korean or Spanish and 
those who failed the attention check question (63 Korean, 21 Spanish). The remaining sample of 276 students who self-identified as Korean (173 women, 102 men, 1 participant of undisclosed sex; $\left.M_{\text {age }}=21.62, S D=1.98\right)$ and 191 Spanish students who identified themselves as Spanish (138 women, $\left.53 \mathrm{men} ; M_{\mathrm{age}}=21.85, S D=4.27\right)$ were included in the analysis. Subjective Socioeconomic status (SES) of both samples were around the middle class: $M_{\text {Korea }}=4.16, S D=1.14$ and $M_{\text {Spain }}=4.73, S D=1.01(1=$ The highest SES; $8=$ The lowest SES). Participants received course credit in exchange for their participation. Participant (victim)'s (those who react to uncivil behaviors) social power (low vs. high) and perpetrator's (those who exhibit uncivil behaviors) social power (low vs. high) were experimentally manipulated; all participants were randomly assigned to one of four perpetrator $\mathrm{x}$ victim conditions in relation to hierarchical positions (see Table 1).

Insert Table 1

\section{Procedure}

Participants who agreed to take part in what was described as a study on behaviors in organizations first completed two questions about cultural values (power distance orientation and cultural tightness-looseness). They were then asked to imagine themselves working in the company. Next, in order to manipulate hierarchical position in the organization, participants were assigned randomly to read one of four imaginary scenarios regarding the declining a request from a colleague whose position is either higher or lower (relative to themselves) or equally high or low in the organization ("In the email, your colleague asks you for feedback on a proposal that is due for submission. However, you are very busy due to an upcoming deadline for your own project, so you decide to decline the request. You email your colleague by saying that you are unable to provide feedback"). The imaginary scenario was adapted from Moon et al. (2018c) and was accompanied by a visual ladder to provide an illustration 
of the hierarchical relationship between the participant and the requester, who was depicted as equidistantly lower or higher or equal on the ladder. This procedure ensures that all participants had a similar understanding of their hierarchical position as compared with their colleagues' one.

After reading the scenario, participants carried out a task in which they wrote an email declining the request. Following the email task, participants were asked to indicate the target's hierarchical position by comparing themselves as a manipulation check and then based on the scenario in which they had declined the request they answered the remaining measures which we describe below.

\section{Materials}

Across measures, we averaged the item scores to form total scores.

Power distance orientation. Power distance orientation was measured by a 6-item scale from Dorfman and Howell (1988). Participants indicated the extent to which they agreed with statements, such as "Employees should not disagree with management decisions" on a 7 -point Likert scale $\left(1=\right.$ strongly disagree, $7=$ strongly agree $; \alpha_{\mathrm{combined}}=.63$, $\left.\alpha_{\text {Korea }}=.60, \alpha_{\text {Spain }}=.72\right)$.

Tightness and Looseness. Tightness-looseness was measured by a 6-item scale from Gelfand et al. (2011). ${ }^{1}$ Using a 7-point Likert scale, participants indicated the extent to which they agreed with statements such as "There are many social norms that people are supposed to abide by in this country". $\left(1=\right.$ strongly disagree, $7=$ strongly agree $; \alpha_{\text {combined }}=.71$, $\left.\alpha_{\text {Korea }}=.61, \alpha_{\text {Spain }}=.64\right)$.

Hierarchical position manipulation check. Participants responded to two manipulation check items that probed impressions of relative hierarchical position vis-à-vis

\footnotetext{
${ }^{1}$ A reversed item ("People in this country have a great deal of freedom in deciding how they want to behave in most situations") was dropped from the analysis due to low communality with the other five (coefficient $<.30$ ).
} 
the colleague who request feedback $(1=$ has much less power and influence than me to $7=$ has much more power and influence than me and $1=$ enjoys much less status and respect than $m e$ to $7=$ enjoys much more status and respect than $m e ; r_{\text {combined }}=.83, r_{\text {Korea }}=.86$, $\left.r_{\text {Spain }}=.79, p \mathrm{~s}<.001\right)$.

Discomfort with incivility. Discomfort, defined as unpleasant subjective state (similar to stress and anxiety), was regarded as an ideal primary outcome of uncivil behaviors (Moon et al., 2018c). Participants indicated how uncomfortable they would feel in response to a series of 22 hypothetical uncivil behaviors which adopted from Moon et al. (2018c; 16 items) and Cortina et al. (2001; 6 items) (e.g., "Not returning my greeting", "Gossiping and criticizing me behind my back", "Making demeaning or derogatory remarks about you", "Put you down or be condescending to you"; 1 = little discomfort to 7 = great discomfort; $\alpha_{\text {combined }}$ $\left.=.92, \alpha_{\text {Korea }}=.90, \alpha_{\text {Spain }}=.93\right)$

Perceived injunctive norm. Participants answered three questions using a 7-point scale to indicate the extent to which they felt the colleague's uncivil behaviors were socially acceptable (e.g., "In general, how socially acceptable/appropriate/legitimate it would be for this person to behave in the ways indicated above?"; 1 = completely unacceptable/inappropriate/illegitimate to 7 = perfectly acceptable / appropriate / legitimate; $\left.\alpha_{\text {combined }}=.71, \alpha_{\text {Korea }}=.70, \alpha_{\text {Spain }}=.73\right)$.

Perceived descriptive norm. Participants indicated how likely and common it was for them to witness these behaviors exhibited by the colleague using the two items ("In general, how likely is it to witness people in a colleague in a lower [higher] position acting in the ways described above after their request being declined by a person in a higher [lower] position (or a person in the same lower [higher] position)?"; $1=$ not very likely at all to $7=$ to extremely likely, 'In general, how 'common' is it that a colleague in a lower [higher] position would behave in the ways described above after their request being declined by a person in a 
higher [lower] position (or a person in the same lower [higher] position)?"; $1=$ not very common at all to $7=$ extremely common; $\left.r_{\text {combined }}=.73, r_{\text {Korea }}=.76 r_{\text {Spain }}=.67, p s<.001\right)$.

Personal norm. Using a 7-point scale participants indicated the extent to which they would accept the colleague with incivility ("To what extent that you would accept/tolerate/legitimate for this person to behave in the ways indicated above?; $1=$ not accept/tolerate/legitimize at all to $7=$ completely accept/tolerate/ legitimize; $\alpha_{\mathrm{combined}}=.81$, $\left.\alpha_{\text {Korea }}=.80, \alpha_{\text {Spain }}=.79\right)$.

\section{Results}

Descriptive statistics including the correlations between variables, means and standard deviations are presented across cultural groups in Table 2 and separately for each cultural group (Korean vs. Spanish) in Table 3.

Insert Table 2 and 3

\section{Preliminary Analysis}

Manipulation check. Our results suggest that the manipulation worked as expected. We first averaged responses to the two manipulation check questions for perpetrator's social power as compared to victim's social power. A 2 (cultural group: Korean vs. Spanish) x 2 (perpetrator position: low vs. high) x 2 (victim position: low vs. high) ANOVA on this score confirmed that the perpetrator with a higher position $(M=4.77, S D=1.02)$ was perceived to have a higher power and status (i.e., rank) than the perpetrator with a lower position $(M=$ $3.42, S D=.84), F(1,459)=482.04, p<.001, \eta_{\mathrm{p}}{ }^{2}=.51$. In the same vein, the victims (participants) with a lower position perceived their counterpart as holding a higher power and status compared to themselves $(M=4.71, S D=1.03)$ than the victims (participants) with a higher position $(M=3.40, S D=.85), F(1,459)=461.98, p<.001, \eta_{\mathrm{p}}^{2}=.50$. The interaction 
between perpetrator position and victim position was also significant, $F(1,459)=20.49$, $p<$ $.001, \eta_{\mathrm{p}}^{2}=.04$, indicating that the perpetrator with a higher position was perceived to have a higher power an status than the perpetrator with a lower position when the victim's position was lower, $F(1,459)=361.03, p<.001, \eta_{\mathrm{p}}{ }^{2}=.44$, as well as equally higher, $F(1,459)=$ 147.64, $p<.001, \eta_{\mathrm{p}}{ }^{2}=.24$. Another simple effect also showed the same pattern, indicating that the victims with a lower status perceived their counterpart as holding a higher power and status compared to themselves than the victims with a higher position when the perpetrator's position was higher, $F(1,459)=332.17, p<.001, \eta_{\mathrm{p}}^{2}=.42$, as well as equally lower, $F(1$, 459) $=146.75, p<.001, \eta_{\mathrm{p}}^{2}=.24$. Culture did not interact with the experimental conditions.

Cultural value orientations. Firstly, the results from power distance orientation revealed that the individual level of power distance orientation was different between Korean and Spanish participants, $t(465)=2.57, p=.01, \mathrm{CI}_{95 \%}[.04$ to .33 ], indicating that Korean participants' scores of power distance were higher $(M=2.62, S D=.74)$ than Spanish participants' one $(M=2.43, S D=.83)$. Secondly, there was also cultural differences on the level of tightness-looseness, $t(465)=12.94, p<.001, \mathrm{CI}_{95 \%}[.82$ to 1.11$]$, showing that the cultural tightness scores for Korea $(M=5.27, S D=.67)$ were significantly higher than the scores for Spain $(M=4.30, S D=.95)$.

\section{Dependent Variables}

Discomfort with incivility. First, we tested our predictions using a 2 (cultural group: Korean vs. Spanish) x 2 (perpetrator position: low vs. high) x 2 (victim position: low vs. high) analysis of variance with discomfort with incivility as dependent variable. The results revealed a significant main effect of cultural group, $F(1,459)=33.61, p<.001, \eta_{\mathrm{p}}^{2}=.07$; Korean participants reported that they would experience greater discomfort when confronted with uncivil behaviors $(M=5.74, S D=.67)$ compared to Spanish participants $(M=5.31, S D$ 
$=.91)$. Other main effects and interactions were not significant. These results suggest that our hypotheses were nor supported by our data.

In order to further explain the effect of culture on discomfort with incivility, we performed a multiple mediation analysis by treating power distance orientation and tightnesslooseness as mediators (Hayes, model 4). The results showed the significant direct effect, $B=$ $.31, S E=.09, \mathrm{CI}_{95 \%}=.14$ to .48 and indirect effects via both $\mathrm{PDO}, B=-.02, S E=.01, \mathrm{CI}_{95 \%}$ $=-.05$ to -.001 and TL, $B=.14, S E=.05, \mathrm{CI}_{95 \%}=.05$ to .24 .

Injunctive norm. The results revealed a significant main effect of cultural group, $F(1,459)=9.13, p=.003, \eta_{\mathrm{p}}^{2}=.02$, indicating that Spanish participant $(M=2.52, S D=$ 1.21) felt the incivility from their colleagues was more socially acceptable than did Korean participants $(M=2.23, S D=.91)$. Other main effects and interactions with culture were not significant. $^{2}$

Descriptive norm. The analysis yielded a significant main effect of cultural group, $F(1,459)=8.97, p=.003, \eta_{\mathrm{p}}{ }^{2}=.02$, and a significant main effect of victim position, $F(1$, $459)=49.76, p<.001, \eta_{\mathrm{p}}^{2}=.10$, which were qualified by a significant interaction, $F(1,459)$ $=5.32, p=.022, \eta_{\mathrm{p}}^{2}=.011$. Further analysis showed that Spanish participants $(M=4.15, S D$ $=1.50)$ felt that incivility was more likely to be exhibited when they were holding a higher position than did Korean participants $(M=3.45, S D=1.47), F(1,459)=13.66, p<.001, \eta_{\mathrm{p}}{ }^{2}$ $=.03$; we did not find significant differences in the two cultural groups in their ratings of perceived likelihood of occurrence when participant's position was low $\left(M_{\text {Spainish }}=4.72\right.$, $\left.S D_{\text {Spanish }}=1.28 ; M_{\text {Korean }}=4.67, S D_{\text {Korean }}=1.36\right), F<1$. Moreover, the main effect of perpetrator position was significant, $F(1,459)=49.76, p<.001, \eta_{\mathrm{p}}^{2}=.10$, which indicates that both Korean and Spanish participants felt that incivility was displayed more often by

2 We also found the significant interaction effect between perpetrator and victim status on injunctive norm, $F(1$, $459)=6.25, p=.013, \eta_{\mathrm{p}}{ }^{2}=.01$. We decompose further this interaction with simple effects analysis presented in Appendix A. 
individuals in higher positions $(M=4.75, S D=1.31)$ than by individuals in lower positions $(M=3.68, S D=1.47)$. The cultural group x perpetrator position interaction and the three-way interactions were insignificant, $F(1,459)=1.84, p=.176, F<1$, respectively.

Furthermore, we sought to examine cultural difference between Korea and Spain in relation to relative hierarchical positions (perpetrator position is relatively lower than participant's one vs. perpetrator position is relatively higher than participant's one; removing equal conditions between perpetrator and victim positions). The results from a two-way ANOVA (relative hierarchical position $\mathrm{x}$ cultural group) revealed significant main effects of cultural group, $F(1,229)=7.72, p=.006, \eta_{\mathrm{p}}^{2}=.033$ and relative perpetrator position, $F(1$, 229) $=125.08, p<.001, \eta_{\mathrm{p}}{ }^{2}=.35$, which were qualified by a significant interaction, $F(1$, $229)=7.08, p=.008, \eta_{\mathrm{p}}^{2}=.03$ (see Figure 1a). Further analysis showed that Spanish participants $(M=3.78, S D=1.53)$ felt that incivility was more likely to be exhibited when their position was higher than the perpetrator as compared with Korean participants $(M=$ 2.86, $S D=1.33), F(1,229)=14.65, p<.001, \eta_{\mathrm{p}}{ }^{2}=.06$; the two cultural groups did not differ in their ratings of perceived likelihood of occurrence when participant's position was lower than the perpetrator $\left(M_{\text {Spainish }}=5.22, S D_{\text {Spanish }}=1.07 ; M_{\text {Korean }}=5.20, S D_{\text {Korean }}=1.10\right), F<1$. Furthermore, both Korean and Spanish participants felt that incivility was displayed more often when their position was lower than the perpetrator $\left(M_{\text {Korean }}=5.20, S D_{\text {Korean }}=1.10\right.$; $\left.M_{\text {Spainish }}=5.22, S D_{\text {Spanish }}=1.07\right)$ than when their position was higher than the perpetrator $\left(M_{\text {Korean }}=2.86, S D_{\text {Korean }}=1.33 ; M_{\text {Spainish }}=3.78, S D_{\text {Spanish }}=1.53\right), F_{\text {Korean }}(1,229)=120.02, p$ $<.001, \eta_{\mathrm{p}}^{2}=.344, F_{\text {Spanish }}(1,229)=30.23, p<.001, \eta_{\mathrm{p}}^{2}=.117$.

Personal norm. The results revealed a significant main effect of cultural group, $F(1$, $459)=40.51, p<.001, \eta_{\mathrm{p}}^{2}=.08$, which was qualified by a significant interaction between cultural group and victim position, $F(1,459)=4.01, p=.046, \eta_{\mathrm{p}}{ }^{2}=.01$. Further analysis showed that Korean participants found that incivility was more acceptable when their 
position was low $(M=3.15, S D=1.11)$ compared with when their position was high $(M=$ $2.89, S D=1.07), F(1,459)=4.30, p=.039, \eta_{\mathrm{p}}^{2}=.01$. In contrast, we did not find significant differences when Spanish participants responded to incivility regarding of their hierarchical position $(M \mathrm{~s}=2.31$ vs. $2.44, S D s=1.05$ vs. 1.12$), F<1 .^{3}$

Again, the results from a two-way ANOVA (relative hierarchical position x cultural group) revealed a significant main effect of cultural group, $F(1,229)=16.49, p<.001, \eta_{\mathrm{p}}^{2}=$ .03 , which was qualified by a significant interaction between cultural group and relative perpetrator position, $F(1,229)=4.58, p=.033, \eta_{\mathrm{p}}{ }^{2}=.02$ (see Figure $1 \mathrm{~b}$ ). A simple effect showed that Korean participants found that incivility exhibited by the perpetrator who has a higher position than themselves was more acceptable $(M=3.40, S D=1.09)$ than incivility exhibited by the perpetrator who has a lower position than themselves $(M=2.88, S D=1.07)$, $F(1,229)=7.73, p=.006, \eta_{\mathrm{p}}^{2}=.033$. In contrast, we did not find significant differences when Spanish participants responded to incivility regarding of the relative hierarchical position of the perpetrator $(M \mathrm{~s}=2.48$ vs. $2.59, S D \mathrm{~s}=1.17$ vs. 1.16$), F<1$. An inspection of cultural differences within each relative perpetrator position condition revealed that Korean participants $(M=3.40, S D=1.09)$ felt it was more acceptable for the perpetrator with a higher position to exhibit incivility than did Spanish participants $(M=2.48, S D=1.17), F(1$, 229) $=19.40, p<.001, \eta_{\mathrm{p}}{ }^{2}=.078$; the two groups did not shown significant differences in their ratings of social acceptability when the perpetrator's position was low $\left(M_{\text {Korean }}=2.88\right.$, $\left.S D_{\text {Korean }}=1.07 ; M_{\text {Spainish }}=2.59, S D_{\text {Spanish }}=1.16\right), F(1,229)=1.83, p=.178$. The main effect of relative perpetrator position was insignificant, $F(1,229)=1.89, p=.171$.

\section{Moderated Mediation Analysis}

\footnotetext{
${ }^{3} \mathrm{We}$ also found the significant interaction effect between perpetrator and victim status on personal norm, $F(1$, $459)=6.93, p=.009, \eta_{\mathrm{p}}{ }^{2}=.02$. We decompose further this interaction with simple effects analysis presented in Appendix A.
} 
We found cross-cultural differences in the effect of hierarchical positions on normative judgements (injunctive, descriptive and personal norms). We also observed significant correlations between mediators (injunctive and personal norms; not descriptive norm) and outcome variable (see Table 1). Based on this, we performed a moderated mediation analysis following the procedure outlined in Hayes (2018, Model 7) to test if there would be conditional indirect effects of relative perpetrator position on perceived discomfort via injunctive and personal norms. In this exploratory model, relative perpetrator position served as a predictor variable (IV: coded $0=$ low, $1=$ high), perceived discomfort served as outcome variable (DV), injunctive (social acceptability) and personal (personal acceptability) norms were treated as mediators and cultural group ( $\operatorname{coded} 0=$ Spain, $1=$ Korea) was served as a moderator.

Both injunctive and personal norms emerged as reliable predictors of discomfort, $B=$

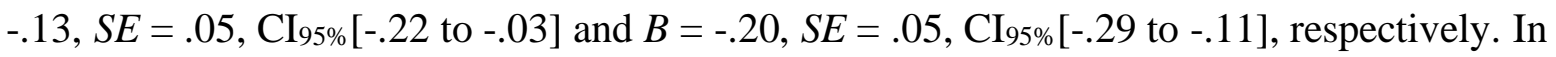
the Spanish sample, the relative perpetrator position did not have an indirect effect on discomfort via injunctive norm, $B=.002, S E=.02, \mathrm{CI}_{95 \%}[-.04$ to .04$]$, and via personal norm, $B=.01, S E=.03, \mathrm{CI}_{95 \%[-.03}$ to .07$]$. Conversely, in the Korean sample, the relative perpetrator position had an indirect effect on discomfort via both injunctive norm, $B=-.03$, $S E=.02, \mathrm{CI}_{95 \%}\left[-.07\right.$ to -.01], and personal norm, $B=-.05, S E=.02, \mathrm{CI}_{95 \%}[-.11$ to -.01] (see Figure 2a). Thus, compared with Spanish participants, Korean participants found that incivility exhibited by the perpetrator who hold a higher position than themselves was more socially and personally acceptable than incivility exhibited by the perpetrator who hold a lower position than themselves, as a result their levels of discomfort became lower vis-à-vis a high-ranking perpetrator compared to a low-ranking perpetrator. In sum, the significant 
indirect path relative perpetrator position to discomfort through the parallel influence of injunctive norm and personal norm was observed in the Korean sample only. ${ }^{4}$

Furthermore, given the role of power distance orientation at an individual level on people's reaction to downward mistreatment (Lian et al., 2012; Lin et al., 2013; Liu et al., 2013; Wang et al., 2012), we performed a moderated mediation analysis (Model 11) by treating power distance orientation and tightness-looseness as two moderators and injunctive and personal norms as two mediators. The results showed that the indirect effect of relative perpetrator position on discomfort via injunctive and personal norms were moderated by PDO and TL across cultural groups; these indirect effects were only significant among individuals who endorsed stronger power distance and tightness-looseness values, $B_{\text {InjunctiveNorm }}=-.05, S E=.03, \mathrm{CI}_{95 \%}[-.11$ to -.01$], B_{\text {PersonalNorm }}=-.10, S E=.04, \mathrm{CI}_{95 \%}[-.19$ to $.03]$.

\section{Discussion}

In this research, for the first time, we investigated whether there are cultural differences in individuals' normative reactions to incivility using the samples from Korea and Spain. Results from the present study showed differences between these two countries, which contribute to the areas of culture, power and the workplace mistreatment literature in many important ways.

Although there was no interaction between relative perpetrator status and cultural group on the perceived discomfort, interestingly the perceived level of discomfort of

\footnotetext{
${ }^{4}$ Furthermore, we performed a moderated serial mediation analysis following the procedure outlined in Hayes (2018, Model 83) to test if there would be conditional indirect effects of relative perpetrator position on perceived discomfort. The indirect path relative perpetrator position to perceived discomfort via injunctive norm (mediator 1) and personal norm (mediator 2) was significant in the Korean society, $B=-.02, S E=.01$,

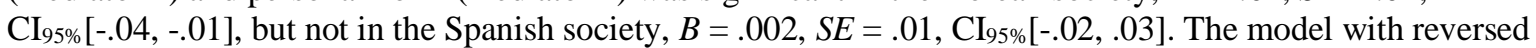
order of mediators (personal norm $\rightarrow$ injunctive norm) was also significant in the Korean society, $B=-.01, S E$ $=.01, \mathrm{CI}_{95 \%}[-.03,-.002]$, but not in the Spanish society, $B=.002, S E=.01, \mathrm{CI}_{95 \%}[-.01, .02]$. Thus, the significant indirect paths relative perpetrator position to discomfort through the sequential influence of injunctive norm and personal norm were observed in the Korean sample only.
} 
incivility was higher among Korean participants than Spanish participants. Our further mediation results suggest that this cultural difference might be because of Korean's stronger endorsement of power distance and tightness-looseness values; Koreans would experience less discomfort via stronger endorsement of power distance, but they would experience greater discomfort via stronger endorsement of tightness-looseness.

As a culture specific rationale, we found that compared with Spanish, Korean participants would perceive that it is more (less) personally acceptable for incivility of power holders (powerless individuals), which can be explained through the cultural difference on tightness/looseness that social norms are tighter in the Korean society than in the Spanish society (Gelfand et al., 2006; Gelfand et al., 2011). The results can extend the previous findings that compared with British, Koreans are more likely to accept the mistreatment from senior individuals (Moon et al., 2018c). Thus, Koreans reactions to incivility are more sensitive to the interaction partner's hierarchical positions compared to themselves. Even their communication style and its level of politeness can vary depending on who they are interacting with in social interactions (Moon et al., 2019). Moreover, the present findings can convey important meanings to the conflict management in the context of intercultural negotiations as globalization continue to bring people from diverse cultural background. Interpersonal conflict in the role expectation of the relationship between manager and subordinates can arise when the role expectations from manager and subordinates are not matched due to the influences of status differences and cultural values. For example, high status negotiators with higher endorsement of power distance paired with low status negotiators with lower endorsement of power distance are prone to experience more anger, place less emphasis on cooperative interaction goals, exchange less information about preferences and priorities, use less distributive positioning, and consequently, gain less profit than high status negotiators with lower endorsement of power distance paired with low status 
negotiators with higher endorsement of power distance (Liu et al., 2019). Power distance also significantly associated with not only dominating and avoiding styles in conflict situations but also competitive negotiation styles (Caputo et al., 2018; Caputo et al., 2019; Gunkel et $a l .$, 2016). Thus, building upon this, future research is required to extend the present findings in the contexts of conflict managements and negotiations.

Using a moderated mediation analysis, we provided an important exploratory evidence for the idea that the indirect effect of perpetrator's hierarchical position on discomfort via injunctive and personal norms are moderated by cultural groups at a collective level. Specifically, we observed that compared with Spanish participants, Korean participants reported that it is more socially and personally acceptable for incivility exhibited by the perpetrator who hold a higher position than themselves, in turn their levels of discomfort became lower vis-à-vis a perpetrator in a powerful position compared to a perpetrator in a powerless position. Thus, our results significantly extended a direct previous research that compared British and Korean individuals (Moon et al., 2018c) by including a new norm (personal norm) as well as by comparing Spanish and Korean people. Additionally, given perceived injunctive norm and personal norm jointly affect people's behaviors (Krueger, 1996; see Morris et al., 2015, for a review), we explored this moderated mediation model by treating the two mediators in conjunction (perceived injunctive norm $\rightarrow$ personal norm; personal norm $\rightarrow$ perceived injunctive norm), which turned out the both directions were significant suggesting that the perceived injunctive norm and personal norm play a role in a similar manner in the design of the present study. In a similar vein, we also found that individual's power distance and tightness/looseness values moderated the indirect effect of relative perpetrator position on discomfort via injunctive and personal norms. This result can extend the previous research that individual's cultural value such as power distance can affect their psychological reactions to downward mistreatment (e.g., Lian et al., Brown, 2012; Lin 
et al., Chen, 2013; Liu et al., 2013; Wang et al., 2012). Although findings from the moderated mediation analyses were significant, the results were exploratory. Therefore, in order to confirm validly the findings, future research should examine using a preregistered design with strong hypotheses.

Interestingly, albeit both Spanish and Koreans felt the higher frequency of uncivil behaviors from the powerholders compared with powerless people, there was cultural differences on the perception of descriptive norms, indicating that Spanish participants felt that incivility was more likely to be exhibited when they were holding a higher position than did Korean participants. This might also be associated with the fact that social norms regarding hierarchical roles in interpersonal relationships operate less tightly in Spanish society.

Although our analysis strategy prevents us inferring similarities between countries, the lack of significant differences found might suggest analogies between these two countries. In the perception of descriptive norms, we found that both Korean and Spanish people perceived that incivility is likely to be exhibited more often by individuals in higher positions than by individuals in lower positions. This finding is compatible with the existing evidence that interpersonal mistreatment such as incivility is more commonly displayed by those who hold a power (e.g., Cortina et al., 2001; Lim and Lee, 2011; Moon et al., 2018c; Pearson et al., 2000; Torelli and Shavitt, 2010). In the perceptions of injunctive and personal norms, we observed that both Korean and Spanish people perceived that the incivility is more socially and personally acceptable when the perpetrator (victim)'s position was higher (lower) than the victim (perpetrator) as compared with when the positions of perpetrator and victim were equally high (low), which can be reasoned based on the small difference on the cultural dimension of power distance so that both Korea and Spain may be classified as higher power distance countries (Hofstede et al., 2010) (see Appendix A). 
In sum, we observed both cultural differences and lack of differences in the present research. We interpreted the current findings for cultural differences with a theoretical rationale that social norms operate much tightly in the Korean society; the embedded hierarchical norms may be much stronger and the deviation from the norm may be more strictly sanctioned in Korean society than in Spanish society (Gelfand et al., 2011). Furthermore, we interpreted the present findings for cultural similarities with a theoretical rationale that both Korea and Spain are categorized as higher power distance countries at a national level and their scores of power distance index were similar (Hofstede et al., 2010). Thus, based on our findings with the theoretical rationales we would like to conclude that cultural differences and similarities can co-exist between Korean and Spanish societies and the roles of descriptive norm and injunctive norm are distinctive, but the roles of injunctive norms and personal norms might be similar in this context of incivility associated with hierarchical relationships as a social context.

\section{Practical Implications}

Based on the results of the present study, we can draw an important lesson for practice. Organizations should consider carefully about the influence of power distance at individual, organizational and cultural levels because higher power distance may lead to higher acceptability of downward mistreatment by victims (Lian et al., 2012; Moon et al., 2018c; Wang et al., 2012). How can organizations minimize downward incivility in work context? First, it is very important to develop sustainable organizational cultures and climates which promote and preserve ethical work environments where workplace incivility is discouraged. The present work suggests that culture can shape individuals' perception and affective responses. In other words, organizational cultures and climates supporting higher power distance may cause a risk to ethical climates and be more tolerant to the negative impacts of workplace incivility, especially displayed by those in powerful positions. This 
effect of power distance on employee's normative reactions may also be strengthened by how norms are tightly (vs. loosely) embedded in groups and societies. Individuals with higher endorsement of power distance orientations and tightness may be more acceptable for the powerful perpetrator's uncivil behaviors. Thus, in a globalized world, organizations should understand and acknowledge cultural dynamics at national and individual levels to create ethical work environments.

In addition, formal policies of organizations such as codes of ethics can help prevent workplace incivility. Presenting clear disciplinary guidelines for employee may affect the reinforcement of injunctive norms. For example, when people focus on injunctive norms (i.e., behaviors that are acceptable for powerful or powerless individuals to engage in), their engagement in unethical behaviors was low (Hu et al., 2016). Thus, presence and application of clear policies would be not only discouraging for perpetrators but also encouraging victims to express their voice in the context of incivility. Policy might be particularly helpful for low status victims in high power distance cultures. Indeed, when Korean (vs. British) organizations prescribed ethical rules regarding the relationship between subordinates and manages in codes of ethics, they focused more on influences of hierarchy in behavioral prescriptions (Moon et al., 2018b).

\section{Strengths, Limitations and Future Works}

In the previous power research, there is a prevalent problem that a baseline or control condition were not included in many findings (see Lammers and Burgmer, 2017) as well as the used control or baseline conditions were not completely related to the high- and lowpower conditions (see Magee and Smith, 2013). In order to establish the strength of the effect of relative hierarchical position between the perpetrator and victim, the present research includes equal conditions (equally high or low in the hierarchical relationship between perpetrator and victim [participant]) in the experimental manipulations. Nonetheless, our 
experiment in artificial settings using student samples may have low ecological validity, which could limit the possibility of findings to be generalized to natural setting with nonstudent samples. In order to generalize our findings to real world, future research should be examined based on participant's actual experience of incivility in the workplaces.

Although we found significant indirect effects of the hierarchical position of perpetrator (victim) on perceived level of discomfort through the perceived norms (descriptive, injunctive and personal norms), unlike the previous work (Moon et al., 2018c) we failed to observe the direct effect on the outcome variable showing that participants who joined in the present study may have felt it was uncomfortable for incivility as it is regardless of the effects of cultural settings (Korea vs. Spain) and social context (i.e., hierarchical relationship). This inconsistent finding might be because the difference of individuals' power distance endorsement between South Korea and Spain was small. In addition, another possible cause is that the present research did not match the participant's gender with the gender of the perpetrator. However, the genders of the participant and the perpetrator were matched in Moon et al. (2018c)'s work in which they considered there may be the effect of gender on individuals' responses to mistreatment (Aquino and Douglas, 2003) as power, hierarchy and norms are sometimes related to gender (e.g., Eagly and Wood, 1982; Ridgeway, 2001). Future research is required to check whether the findings from the present or previous research are replicated in the same cultural contexts by matching the participant's gender with the gender of the perpetrator.

Another limitation of this research is that the cross-cultural comparison was conducted with a European country (Spain), high power distance cultural group and social norms are loosely embedded in the society, and an East Asian country (South Korea), high power distance cultural group and social norms are tightly embedded in the society. Although we provided evidences for cross-cultural differences, it may be difficult to determine whether 
resulting cultural differences are due to cultural level variables or other factors by using only two cultural groups (see Fischer and Poortinga, 2018; van de Vijver and Leung, 2000) because the present findings are impossible to be generalized by the two-group comparison albeit the included samples can be representative of each cultural group. Future research should therefore examine the effect of hierarchical positions of the perpetrator (victim) on individuals' normative reactions to incivility across a wider range and higher number of cultural settings. For instance, Japan, India and Singapore can be similarly clustered to South Korea but Greece, Brazil and Venezuela can be akin to Spain.

The present study focuses on the perceived level of discomfort as a main outcome variable which can measure general negative emotion. Future research should examine the association between individuals' emotional reactions and their relationship with the perpetrator in different hierarchical positions by considering the other emotions so that we can understand more about people's reactions to incivility exhibited by powerful and powerless individuals. For example, in daily life, people felt more embarrassed when they experienced incivility provoked by powerful perpetrator (Hershcovis et al., 2017). Also, other emotions such as anger, fear and sadness were used to investigate people's reactions to workplace incivility (Porath and Pearson, 2012). Moreover, future work should also consider measuring organizational outcomes such as job satisfaction, job performance and turnover intentions in the context of incivility. Indeed, there is an evidence that the relationship between coworker incivility and organizational outcomes are mediated by emotional exhaustion (Hur et al., 2015). Also, in low power distance cultural settings, some organizational outcomes are negatively affected by senior colleagues' uncivil behaviors (cf. Hershcovis and Barling, 2010). Thus, it is important to include other emotional and organizational outcome variables in the future study. 
In the present work, we focus on the situational and cultural factors. However, recent evidences suggest that individuals' reactions to incivility may also be affected by dispositional (e.g., narcissism) and organizational factors (e.g., norms, structures and climates) (Liu et al., 2020; Moon et al., 2020; Moon et al. 2018c; Schilpzand et al., 2016; Tepper et al., 2017). Future research can extend the present findings by considering the role of dispositional and organizational factors and their interaction with cultural factors on how people react to workplace incivility.

Finally, there are evidences that individuals' cultural values can vary within the same cultural setting based on dispositional traits or due to contextual factors (Leung and Cohen, 2011; Mendoza-Denton and Mischel, 2007; Moon et al., 2018a). Even though collective levels of power distance suggest the differences between countries (Hofstede et al., 2010), it is also possible that power distance vary at an individual level (e.g., Kirkman et al., 2009). It is also true that the collective levels of tightness/looseness suggest the differences between societies (Gelfand et al., 2011), states or organizations (e.g., Harrington and Gelfand, 2014; Lee and Kramer, 2016). Although it may not be possible to treat tightness/looseness at an individual level because these terms related to the multilevel system of the strength of social norms (Li et al., 2017), past research found that culturally tighter (vs. looser) societies incorporate the strong relationship between cultural values (i.e., individualism/collectivism and horizontal/vertical cultural orientations) and outcome variables (e.g., the tendency of cooperating with others) (Taras et al., 2010). In other words, it is possible that individuals' behaviors are influenced by the dominant cultural orientation across situations in tight societies (Torelli and Rodas, 2017). Likewise, it may be true that our present exploratory findings support this rationale, but future research should examine whether the findings from the present research at the macro level comparing between countries can be also found at the individual level with a preregistered design and strong hypotheses. 


\section{Conclusion}

To the best of our knowledge, this is the first time of a cross-cultural comparison using under-investigated Korean and Spanish settings in the context of incivility. We found evidence that individuals' occupational status affects their normative reactions to incivility similarly as well as differently across cultural groups. In higher power distance cultures (Korea and Spain), people perceive that uncivil actions are more commonly displayed by a powerholder (vs. powerless) in the organizational contexts but they feel they were more social and personally acceptable attesting to the interactive influence of subjective social norms (descriptive and injunctive) and personal norm. However, we also observed crosscultural differences in people's normative reactions, which might be caused by the higher influences of norms regarding social hierarchy in Korea (tightly influenced) compared with in Spain (loosely influence). Furthermore, this pattern of cultural differences was observed at an individual level of cultural value endorsement. All in all, the findings highlight cultural influences on the importance of social hierarchy as a factor that can impact the people's normative reactions to incivility. 


\section{References}

Andersson, L. M. and Pearson, C. M. (1999). "Tit for tat? The spiraling effect of incivility in the workplace", Academy of Management Review, Vol. 24 No. 3, pp. 452-471.

Aquino, K. and Douglas, S. (2003). "Identity threat and antisocial behavior in organizations: The moderating effects of individual differences, aggressive modeling, and hierarchical status", Organizational Behavior and Human Decision Processes, Vol. 90 No. 1, pp. $195-208$.

Aquino, K., Lewis, M. U. and Bradfield, M. (1999). "Justice constructs, negative affectivity, and employee deviance: A proposed model and empirical test", Journal of Organizational Behavior, Vol. 20 No. 7, pp. 1073-1091.

Aquino, K., Tripp, T. M. and Bies, R. J. (2001). "How employees respond to personal offense: the effects of blame attribution, victim status, and offender status on revenge and reconciliation in the workplace", Journal of Applied Psychology, Vol. 86 No. 1, pp. $52-59$.

Bowles, H. R. and Gelfand, M. (2010). "Status and the evaluation of workplace deviance", Psychological Science, Vol. 21 No. 1, pp. 49-54.

Bowling, N. A. and Beehr, T. A. (2006). "Workplace harassment from the victim's perspective: a theoretical model and meta-analysis", Journal of Applied Psychology, Vol. 91 No. 5, pp. 998-1012.

Caputo, A. (2013). "A literature review of cognitive biases in negotiation processes", International Journal of Conflict Management, Vol. 24 No. 4, pp. 374-398.

Caputo, A., Ayoko, O. B. and Amoo, N. (2018). "The moderating role of cultural intelligence in the relationship between cultural orientations and conflict management styles", Journal of Business Research, Vol. 89, pp. 10-20. 
Caputo, A., Ayoko, O. B., Amoo, N. and Menke, C. (2019). "The relationship between cultural values, cultural intelligence and negotiation styles", Journal of Business Research, Vol. 99, pp. 23-36.

Conway, M., Di Fazio, R. and Mayman, S. (1999). "Judging others' emotions as a function of the others' status”, Social Psychology Quarterly, Vol. 62 No. 3, pp. 291-305.

Cortina, L. M., Magley, V. J., Williams, J. H. and Langhout, R. D. (2001). "Incivility in the workplace: Incidence and impact”. Journal of Occupational Health Psychology, Vol. 6 No. 1, pp. 64-80.

Cortina, L. M. (2008). “Unseen injustice: Incivility as modern discrimination in organizations", Academy of Management Review, Vol. 33 No. 1, pp. 55-75.

Dorfman, P. W. and Howell, J. P. (1988). "Dimensions of national culture and effective leadership patterns: Hofstede revisited", Advances in International Comparative Management, Vol. 3 No. 1, pp. 127-150.

Eagly, A. H. and Wood, W. (1982). "Inferred sex differences in status as a determinant of gender stereotypes about social influence”, Journal of Personality and Social Psychology, Vol. 43 No. 5, pp. 915-928.

Faul, F., Erdfelder, E., Buchner, A. and Lang, A. G. (2009). “Statistical power analyses using G* Power 3.1: Tests for correlation and regression analyses", Behavior Research Methods, Vol. 41 No. 4, pp. 1149-1160.

Fischer, R. and Poortinga, Y. H. (2018). "Addressing methodological challenges in culturecomparative research", Journal of Cross-Cultural Psychology, Vol. 49 No. 5, pp. 691712.

Fiske, S. T. (2004). Social beings: A core motives approach to social psychology. Wiley, New Brunswick.

Friedman, T. L. (2005). The world is flat. Farrar, Straus \& Giroux, NY. 
Galinsky, A. D., Magee, J. C., Gruenfeld, D. H., Whitson, J. A. and Liljenquist, K. A. (2008). "Power reduces the press of the situation: implications for creativity, conformity, and dissonance", Journal of Personality and Social Psychology, Vol. 95 No. 6, pp. 14501466.

Gelfand, M. J., Aycan, Z., Erez, M. and Leung, K. (2017). “Cross-cultural industrial organizational psychology and organizational behavior: A hundred-year journey", Journal of Applied Psychology, Vol 102 No. 3, pp. 514-529.

Gelfand, M. J., Erez, M. and Aycan, Z. (2007). "Cross-cultural organizational behavior”, Annual Review of Psychology, Vol 58, pp. 479-514.

Gelfand, M., Jackson, J. C., Pan, X., Nau, D., Dagher, M. and Chiu, C. Y. (2020). “Cultural and Institutional Factors Predicting the Infection Rate and Mortality Likelihood of the COVID-19 Pandemic", available at https://doi.org/10.31234/osf.io/m7f8a (accessed 1 April 2020).

Gelfand, M. J., Nishii, L. H. and Raver, J. L. (2006). “On the nature and importance of cultural tightness-looseness", Journal of Applied Psychology, Vol. 91 No. 6, pp. 12251244.

Gelfand, M. J., Raver, J. L., Nishii, L., Leslie, L. M., Lun, J., Lim, B. C., ... and Aycan, Z. (2011). "Differences between tight and loose cultures: A 33-nation study", Science, Vol. 332 No. 6033, pp. 1100-1104.

Gunkel, M., Schlaegel, C. and Taras, V. (2016). "Cultural values, emotional intelligence, and conflict handling styles: A global study", Journal of World Business, Vol. 51 No. 4, pp. $568-585$.

Günsoy, C. (2019). "Rude bosses versus rude subordinates: How we respond to them depends on our cultural background", International Journal of Conflict Management, Vol. 31 No. 2, pp. 175-199. 
Harrington, J. R. and Gelfand, M. J. (2014). "Tightness-looseness across the 50 united states", Proceedings of the National Academy of Sciences, Vol. 111 No. 22, pp. 79907995.

Hayes, A. F. (2018). Introduction to mediation, moderation, and conditional process analysis: A regression-based approach (2nd ed.), Guilford Press, New York, NY.

Hershcovis, M. S. and Barling, J. (2010). "Towards a multi-foci approach to workplace aggression: A meta-analytic review of outcomes from different perpetrators", Journal of Organizational Behavior, Vol. 31 No. 5, pp. 24-44.

Hershcovis, M. S., Ogunfowora, B., Reich, T. C. and Christie, A. M. (2017). “Targeted workplace incivility: The roles of belongingness, embarrassment, and power", Journal of Organizational Behavior, Vol. 38 No. 7, pp. 1057-1075.

Hofstede, G., Hofstede, G. J. and Minkov, M. (2010). Cultures and organizations: Software for the mind. McGraw-Hill, NY.

House, R. J., Hanges, P. J., Javidan, M., Dorfman, P. W. and Gupta, V. (2004). Culture, leadership, and organizations: The GLOBE study of 62 societies. Sage, Newbury Park, CA.

Hu, M., Rucker, D. D. and Galinsky, A. D. (2016). "From the immoral to the incorruptible how prescriptive expectations turn the powerful into paragons of virtue", Personality and Social Psychology Bulletin, Vol. 42 No. 6, pp. 826-837.

Hur, W. M., Kim, B. S. and Park, S. J. (2015). “The relationship between coworker incivility, emotional exhaustion, and organizational outcomes: The mediating role of emotional exhaustion", Human Factors and Ergonomics in Manufacturing \& Service Industries, Vol. 25 No. 6, pp. 701-712.

Hutton, S. and Gates, D. (2008). "Workplace incivility and productivity losses among direct care staff”, AAOHN Journal, Vol. 56 No. 4, pp. 168-175. 
Irum, A., Ghosh, K. and Pandey, A. (2020). "Workplace incivility and knowledge hiding: a research agenda", Benchmarking: An International Journal, Vol. 27 No. 3, pp. 958-980.

Johnson, P. R. and Indvik, J. (2001). "Slings and arrows of rudeness: Incivility in the workplace”, Journal of Management Development. Vol. 20 No. 8, pp. 705-714.

Johnson, T., Kulesa, P., Cho, Y. I. and Shavitt, S. (2005). "The relation between culture and response styles evidence from 19 countries”, Journal of Cross-Cultural Psychology, Vol. 36 No. 2, pp. 264-277.

Kernan, M. C., Watson, S., Fang Chen, F. and Gyu Kim, T. (2011). "How cultural values affect the impact of abusive supervision on worker attitudes", Cross Cultural Management: An International Journal, Vol. 18 No. 4, pp. 464-484.

Kirkman, B. L., Chen, G., Farh, J. L., Chen, Z. X. and Lowe, K. B. (2009). "Individual power distance orientation and follower reactions to transformational leaders: A cross-level, cross-cultural examination", Academy of Management Journal, Vol. 52 No. 4, pp. 744764.

Klein, N. (2002). Fences and windows: Dispatches from the front lines of globalization debate. Flamingo Press, London, UK.

Krueger, J. (1996). "Personal beliefs and cultural stereotypes about racial characteristics", Journal of personality and Social Psychology, Vol. 71 No. 3, pp. 536-548.

Lammers, J. and Burgmer, P. (2017). "Power increases anchoring effects on judgment", Social Cognition, Vol. 35 No. 1, pp. 40-53.

Lammers, J., Stapel, D. A. and Galinsky, A. D. (2010). "Power increases hypocrisy: Moralizing in reasoning, immorality in behavior", Psychological Science, Vol. 21 No. 5, pp. 737-744. 
Lawler, J. J., Walumbwa, F. and Bai, M. (2008). "National culture and cultural effects", in Harris, M. A. (Ed.), The handbook of international human resources research, Taylor \& Francis, New York, pp. 5-28.

Lee, Y. and Kramer, A. (2016). "The role of purposeful diversity and inclusion strategy (PDIS) and cultural tightness/looseness in the relationship between national culture and organizational culture”, Human Resource Management Review, Vol. 26 No. 3, pp. 198208.

Leung, A. K. Y. and Cohen, D. (2011). "Within-and between-culture variation: individual differences and the cultural logics of honor, face, and dignity cultures", Journal of Personality and Social Psychology, Vol. 100 No. 3, pp. 507-526.

Lewis, P. S. and Malecha, A. (2011). "The impact of workplace incivility on the work environment, manager skill, and productivity", JONA: The Journal of Nursing Administration, Vol. 41 No. 1, pp. 41-47.

Li, R., Gordon, S. and Gelfand, M. J. (2017). “Tightness-looseness: A new framework to understand consumer behavior", Journal of Consumer Psychology, Vol. 27 No. 3, pp. 377-391.

Lian, H., Ferris, D. L. and Brown, D. J. (2012). "Does power distance exacerbate or mitigate the effects of abusive supervision? It depends on the outcome", Journal of Applied Psychology, Vol. 97 No. 1, pp. 107-123.

Lim, S. and Lee, A. (2011). "Work and nonwork outcomes of workplace incivility: Does family support help?", Journal of Occupational Health Psychology, Vol 16. No. 1, pp. 95-111.

Lin, W., Wang, L. and Chen, S. (2013). “Abusive supervision and employee well-being: The moderating effect of power distance orientation", Applied Psychology, Vol. 62 No. 2, pp. $308-329$. 
Liu, C., Yang, L. Q. and Nauta, M. M. (2013). "Examining the mediating effect of supervisor conflict on procedural injustice-job strain relations: The function of power distance", Journal of Occupational Health Psychology, Vol. 18 No. 1, pp. 64-74.

Liu, M., Zhu, L. and Cionea, I. A. (2019). "What makes some intercultural negotiations more difficult than others? Power distance and culture-role combinations", Communication Research, Vol. 46 No. 4, pp. 555-574.

Liu, P., Xiao, C., He, J., Wang, X. and Li, A. (2020). "Experienced workplace incivility, anger, guilt, and family satisfaction: The double-edged effect of narcissism”, Personality and Individual Differences, Vol. 154, 109642.

Lively, K. J. (2000). "Reciprocal emotion management: Working together to maintain stratification in private law firms", Work and Occupations, Vol. 27 No. 1, pp. 32-63.

Magee, J. C. and Smith, P. K. (2013). “The social distance theory of power”, Personality and Social Psychology Review, Vol. 17 No. 2, pp. 158-186.

Mendoza-Denton, R. and Mischel, W. (2007). "Integrating system approaches to culture and personality". in Kitayama, S. and Cohen, D. (Eds.), Handbook of cultural psychology, Guilford Press, New York, NY, pp. 175-195.

Moon, C., Morais, C., Randsley de Moura, G. and Uskul, A. K. (2020). "The Role of Organizational Structure and Deviant Status in Employees' Reactions to and Acceptance of Workplace Deviance”, International Journal of Conflict Management. https://doi.org/10.1108/IJCMA-03-2020-0036

Moon, C., Travaglino, G. A. and Uskul, A. K. (2018a). "Social value orientation and endorsement of horizontal and vertical individualism and collectivism: An exploratory study comparing individuals from North America and South Korea", Frontiers in psychology, Vol. 9, p. 2262. 
Moon, C., Uskul, A. K. and Weick, M. (2018b). "On culture, ethics, and hierarchy: How cultural variations in hierarchical relations are manifested in the code of ethics of British and Korean organizations”, Journal of Applied Social Psychology, Vol. 48 No. 1, pp. 1527.

Moon, C., Uskul, A. K. and Weick, M. (2019). "Cultural differences in politeness as a function of status relations: Comparing South Korean and British communicators", Journal of Theoretical Social Psychology, Vol. 3 No. 3, pp. 137-145.

Moon, C., Weick, M. and Uskul, A. K. (2018c). "Cultural variation in individuals' responses to incivility by perpetrators of different rank: The mediating role of descriptive and injunctive norms", European Journal of Social Psychology, Vol 48. No. 4, pp. 472-489.

Morris, M. W., Hong, Y. Y., Chiu, C. Y. and Liu, Z. (2015). "Normology: Integrating insights about social norms to understand cultural dynamics", Organizational Behavior and Human Decision Processes, Vol. 129, pp. 1-13.

Pearson, C. M., Andersson, L. M. and Porath, C. L. (2000). “Assessing and attacking workplace incivility”, Organizational Dynamics, Vol. 29 No. 2, pp. 123-137.

Pearson, C. M. and Porath, C. L. (2005). "On the nature, consequences and remedies of workplace incivility: No time for "nice”? Think again”, Academy of Management Perspectives, Vol. 19 No. 1, pp. 7-18.

Petkanopoulou, K., Rodríguez-Bailón, R., Willis, G. B. and van Kleef, G. A. (2019). "Powerless people don't yell but tell: The effects of social power on direct and indirect expression of anger”, European Journal of Social Psychology, Vol. 49 No. 3, pp. 533547.

Porath, C. L. and Pearson, C. M. (2012). "Emotional and behavioral responses to workplace incivility and the impact of hierarchical status". Journal of Applied Social Psychology, Vol. 42 No. S1, pp. E326-E357. 
Porath, C. L. and Pearson, C. M. (2013). “The price of incivility”, Harvard Business Review, Vol. 91, pp. 115-121.

Porath C.L. and Pearson C.M. (2010), "The cost of bad behavior", Organizational Dynamics, Vol. 39, pp. 64-71.

Ridgeway, C. L. (2001). “Gender, status, and leadership”, Journal of Social Issues, Vol. 57 No. 4, pp. 637-655.

Santos, H. C., Varnum, M. E. and Grossmann, I. (2017). "Global increases in individualism”, Psychological Science, Vol. 28 No. 9, pp. 1228-1239.

Schilpzand, P., De Pater, I. E. and Erez, A. (2016). "Workplace incivility: A review of the literature and agenda for future research", Journal of Organizational behavior, Vol. 37 No. S1, pp. S57-S88.

Schwartz, S. H. (1977). “Normative influences on altruism”. in Berkowitz, L. (Ed.). Advances in experimental social psychology, Academic Press, New York, NY, pp. 221279.

Taras, V., Kirkman, B. L. and Steel, P. (2010). "Examining the impact of culture's consequences: A three-decade, multilevel, meta-analytic review of Hofstede's cultural value dimensions", Journal of Applied Psychology, Vol. 95 No. 3, pp. 405-439.

Tepper, B. J. (2007). “Abusive supervision in work organizations: Review, synthesis, and research agenda", Journal of Management, Vol. 33 No. 3, pp. 261-289.

Tepper, B. J., Simon, L. and Park, H. M. (2017). “Abusive supervision”, Annual Review of Organizational Psychology and Organizational Behavior, Vol. 4, 123-152.

Torelli, C. J. and Rodas, M. A. (2017). “Tightness-looseness: Implications for consumer and branding research", Journal of Consumer Psychology, Vol. 27 No. 3, pp. 398-404.

Torelli, C. J. and Shavitt, S. (2010). "Culture and concepts of power”, Journal of Personality and Social Psychology, Vol. 99 No. 4, pp. 703-723. 
Tsui, A. S., Nifadkar, S. S. and Ou, A. Y. (2007). "Cross-national, cross-cultural organizational behavior research: Advances, gaps, and recommendations", Journal of Management, Vol. 33 No. 3, pp. 426-478.

Tyler, T. R., Lind, E. A. and Huo, Y. J. (2000). "Cultural values and authority relations: The psychology of conflict resolution across cultures", Psychology, Public Policy, and Law, Vol. 6 No. 4, pp. 1138-1163.

Van de Vijver, F. J. and Leung, K. (2000). "Methodological issues in psychological research on culture", Journal of cross-cultural psychology, Vol. 31 No. 1, pp. 33-51.

Vogel, R. M., Mitchell, M. S., Tepper, B. J., Restubog, S. L., Hu, C., Hua, W. and Huang, J. C. (2015). “A cross-cultural examination of subordinates' perceptions of and reactions to abusive supervision”, Journal of Organizational Behavior, Vol. 36 No. 5, pp. 720-745.

Wang, W., Mao, J., Wu, W. and Liu, J. (2012). “Abusive supervision and workplace deviance: The mediating role of interactional justice and the moderating role of power distance”, Asia Pacific Journal of Human Resources, Vol. 50 No. 1, pp. 43-60. 
Table 1.

Samples size in each independent variable

\begin{tabular}{cccc}
\hline \multirow{2}{*}{ Korea } & \multicolumn{3}{c}{ Perpetrator status } \\
\cline { 2 - 4 } & Low & High $^{*}$ & Total \\
\hline Victim Status - Low & 72 & 66 & 138 \\
Victim Status - High & 74 & 64 & 138 \\
Total & 146 & 130 & 276 \\
\hline Spain & \multicolumn{3}{c}{ Perpetrator status } \\
\cline { 2 - 4 } & Low & High $^{*}$ & Total \\
\hline Victim Status - Low & 51 & 49 & 100 \\
Victim Status - High & 44 & 47 & 91 \\
Total & 95 & 96 & 191 \\
\hline
\end{tabular}

Table 2.

Intercorrelations, means, and standard deviations for study variables $\left(N_{\text {tot }}=467\right)$

\begin{tabular}{lccccccc}
\hline \multicolumn{1}{c}{ Measure } & 1 & 2 & 3 & 4 & 5 & 6 & 7 \\
\hline $\begin{array}{l}\text { 1. Discomfort with } \\
\text { incivility }\end{array}$ & - & & & & & & \\
2. Descriptive norm & .08 & - & & & & & \\
3. Injunctive norm & $-.27^{* * *}$ & $.23^{* * *}$ & - & & & & \\
4. Personal norm & $-.28^{* * *}$ & $.13^{* *}$ & $.41^{* * *}$ & - & & & \\
5. Manipulation check & .01 & $.42^{* * *}$ & $.12^{*}$ & .08 & - & & \\
6. Power distance & -.06 & -.00 & .01 & $.13^{* *}$ & -.02 & - & \\
7. Tightness/Looseness & $.25^{* *}$ & -.05 & $-.15^{* *}$ & .04 & -.07 & $.10^{*}$ & - \\
$M_{t o t}$ & 5.56 & 4.20 & 2.35 & 2.76 & 4.07 & 2.54 & 4.87 \\
$S D_{t o t}$ & 0.81 & 1.50 & 1.06 & 1.14 & 1.15 & 0.78 & 0.92 \\
*** $^{*}<.001, * * p<.01, * p<.05$. & & & & & & &
\end{tabular}


Table 3.

Intercorrelations, means, and standard deviations for study variables separately for each cultural group

\begin{tabular}{lccccccc}
\hline \multicolumn{1}{c}{ Measure } & 1 & 2 & 3 & 4 & 5 & 6 & 7 \\
\hline 1. Discomfort with & - & $.15^{*}$ & -.10 & $-.41^{* * *}$ & .05 & -.03 & .10 \\
incivility & .09 & - & $.17^{*}$ & .07 & $.29^{* * *}$ & -.04 & .02 \\
2. Descriptive norm & $-.41^{* * *}$ & $.26^{* * *}$ & - & $.42^{* * *}$ & -.02 & -.03 & -.06 \\
3. Injunctive norm & $-.38^{* * *}$ & $.24^{* * *}$ & $.54^{* * *}$ & - & .03 & .07 & $-.18^{*}$ \\
4. Personal norm & .02 & $.48^{* * *}$ & $.22^{* * *}$ & $.16^{*}$ & - & -.00 & -.02 \\
5. Manipulation check & $-.17^{* *}$ & .05 & .10 & .12 & -.02 & - & .13 \\
6. Power distance & $.19^{* *}$ & .02 & $-.12^{*}$ & -.09 & -.06 & -.04 & - \\
7. Tightness/Looseness & 5.74 & 4.03 & 2.23 & 3.02 & 4.00 & 2.62 & 5.27 \\
$M_{\text {Korea }}(N=276)$ & 0.67 & 1.53 & 0.91 & 1.10 & 1.19 & 0.74 & 0.67 \\
$S D_{\text {Korea }}$ & 5.31 & 4.45 & 2.52 & 2.37 & 4.17 & 2.43 & 4.30 \\
$M_{\text {Spain }}(N=191)$ & 0.91 & 1.41 & 1.21 & 1.09 & 1.08 & 0.83 & 0.95 \\
$S D_{\text {Spain }}$ & & & & & & & \\
\hline
\end{tabular}

Note. Correlations between study variables for Korean participants $(N=276)$ are presented below the diagonal, and correlations for Spanish participants $(N=191)$ are presented above the diagonal. $* * * p<.001, * * p<.01, * p<.05$. 
a. Cultural group $x$ Relative perpetrator position

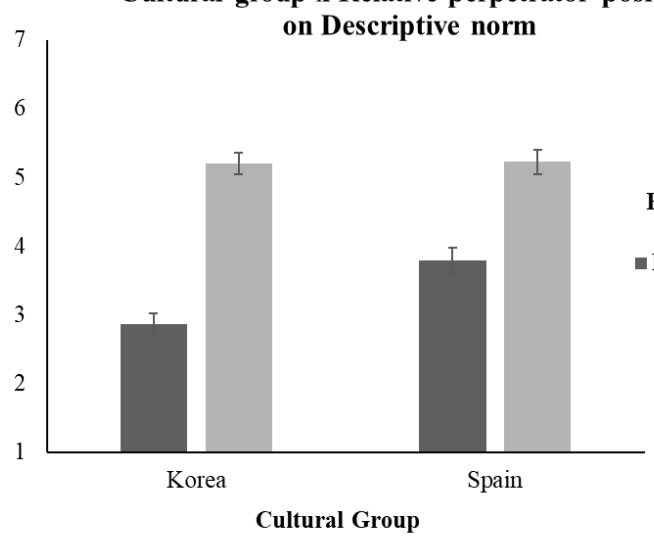

b. Cultural group $\mathrm{x}$ Relative perpetrator position on Personal norm

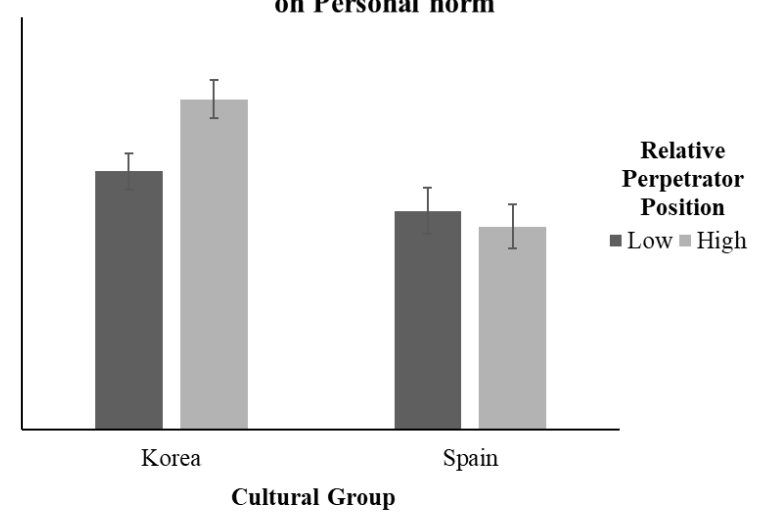

Figure 1. Observed variations in descriptive norm (left column) and personal norm (right column) as a function of relative perpetrator position and cultural group. Error bars represent standard errors of the mean.

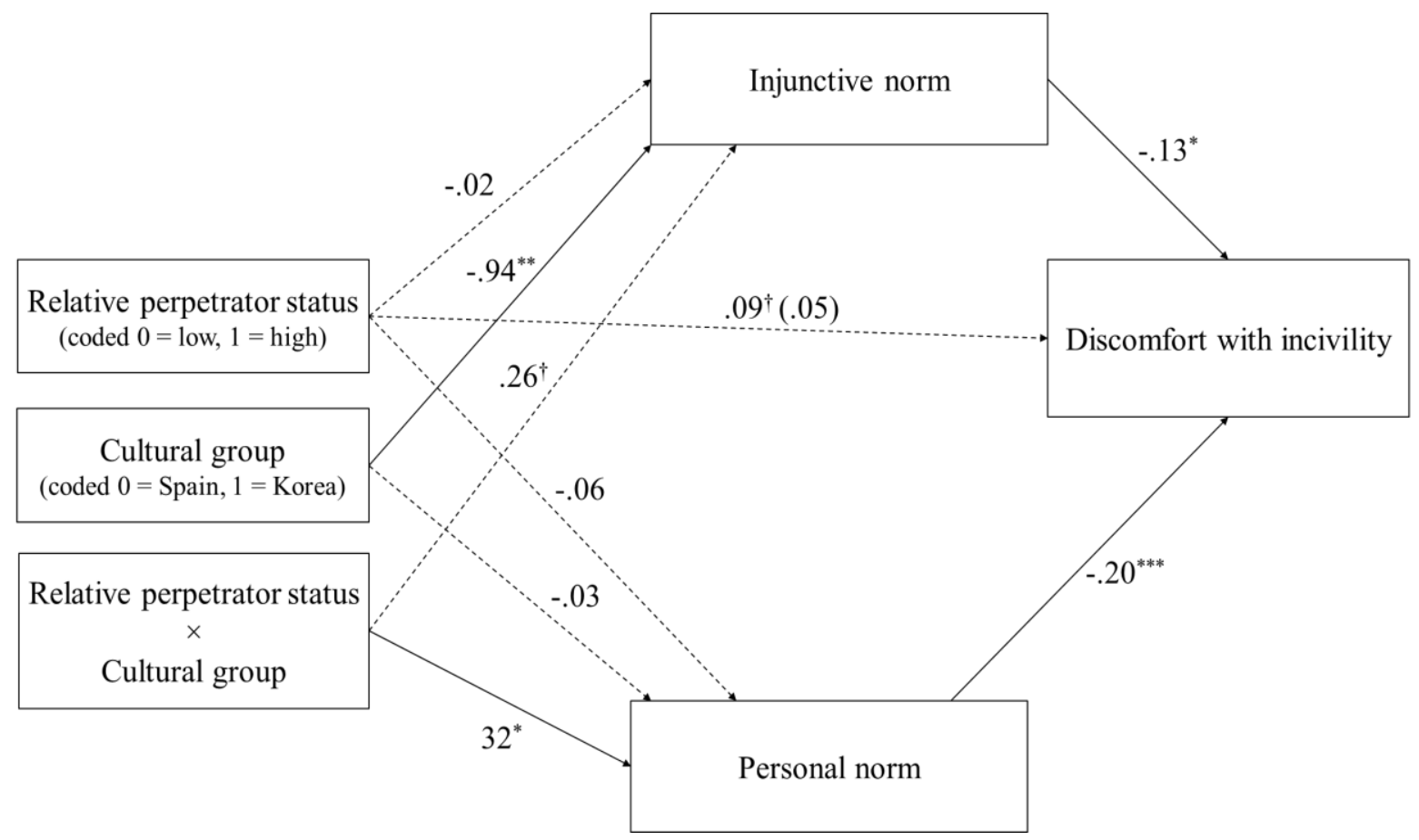

Figure 2. The moderating roles of cultural group on the indirect effects of relative perpetrator status on discomfort caused by uncivil behaviors via injunctive norm and personal norm.

Total direct effect shown in parentheses.

$* * * p<.001, * * p<.01, * p<.05,{ }^{\dagger} p<.10$. 


\section{Appendix A}

Supplementary Analyses for the interaction between perpetrator status and victim status on injunctive and personal norms

\section{Injunctive norm}

There was also significant interaction between perpetrator position and victim position, $F(1$, $459)=6.25, p=.013, \eta_{\mathrm{p}}{ }^{2}=.01$ (see Figure 3a); both Korean and Spanish participants found that the incivility was more acceptable when the perpetrator's position was higher than the victim $(M=2.60, S D=1.12)$ as compared with when the positions of perpetrator and victim were equally high $(M=2.25, S D=.92), F(1,459)=6.48, p=.011, \eta_{\mathrm{p}}^{2}=.014$. In contrast, there was no differences between when the perpetrator's position was lower than the victims $(M=2.31, S D=1.09)$ and when the positions of perpetrator and victim were equally low $(M=$ 2.23, $S D=1.05), F<1$. An inspection of the perpetrator's positional differences within each victim' position condition revealed that both Korean and Spanish participants felt that the incivility was more acceptable when the victim's position was lower than the perpetrator $(M=$ 2.60, $S D=1.12$ ) as compared with when the positions of victim and perpetrator were equally low $(M=2.23, S D=1.05), F(1,459)=6.84, p=.009, \eta_{\mathrm{p}}^{2}=.015$. In contrast, there was no differences between when the victim's position was higher than the perpetrator $(M=2.31$, $S D=1.09)$ and when the positions of victim and perpetrator were equally high $(M=2.25, S D=$ $.92), F<1$. The main effects of perpetrator position and victim position were not significant, $F(1,459)=1.31, p=.252, F(1,459)=1.29, p=.257$, respectively, and cultural group $\mathrm{x}$ victim position interaction and the three-way interactions were not insignificant, $F<1, F(1$, 459) $=1.37, p=.243$, respectively.

\section{Personal norm}

In addition, there was significant interaction effect between perpetrator and victim positions, $F(1,459)=6.93, p=.009, \eta_{\mathrm{p}}{ }^{2}=.02($ see Figure $3 \mathrm{~b})$; both Korean and Spanish 
participants found that the incivility was more acceptable when the perpetrator's position was higher than the victim $(M=3.01, S D=1.21)$ as compared with when the positions of perpetrator and victim were equally high $(M=2.65, S D=1.11), F(1,459)=5.29, p=.022, \eta_{\mathrm{p}}{ }^{2}$ $=.011$. In contrast, there was no differences between when the perpetrator's position was lower than the victims $(M=2.77, S D=1.11)$ and when the positions of perpetrator and victim were equally low $(M=2.60, S D=1.08), F(1,459)=2.01, p=.157$. An inspection of the perpetrator's positional differences within each victim' position condition revealed that both Korean and Spanish participants felt that the incivility was more acceptable when the victim's position was lower than the perpetrator $(M=3.01, S D=1.21)$ as compared with when the positions of victim and perpetrator were equally low $(M=2.60, S D=1.08), F(1,459)=$ $8.24, p=.004, \eta_{\mathrm{p}}{ }^{2}=.018$. In contrast, there was no differences between when the victim's position was higher than the perpetrator $(M=2.77, S D=1.11)$ and when the positions of victim and perpetrator were equally high $(M=2.65, S D=1.11), F<1$. The main effects of perpetrator position and victim position were not significant, $F(1,459)=1.87, p=.172, F<$ 1 , respectively, and cultural group x perpetrator position interaction and the three-way interactions were insignificant, $F(1,459)=1.30, p=.255, F<1$, respectively.
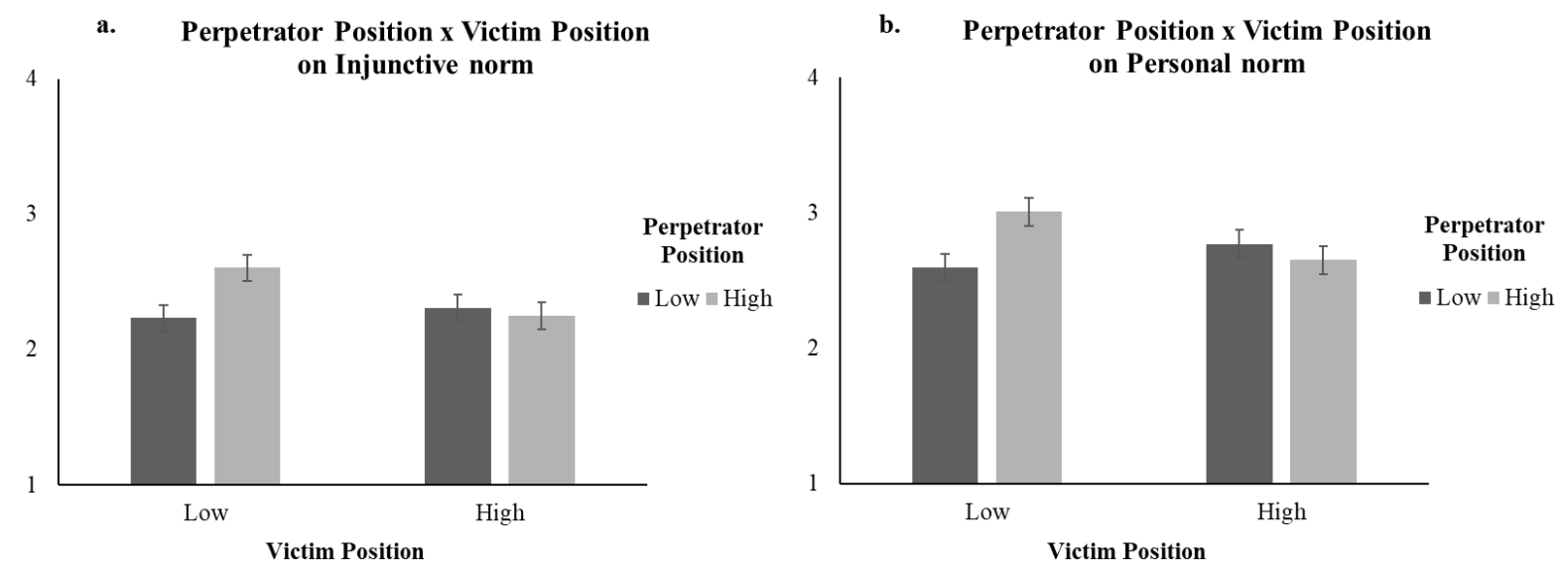

Figure 3. Observed variations in injunctive norm (left column) and personal norm (right column) as a function of perpetrator position and victim position. Error bars represent standard errors of the mean 